\title{
Application and Exploration of Blended Learning Mode in the Teaching of Database Course Design
}

\author{
Peini Shang* \\ School of information engineering, Yulin University, Yulin, Shaanxi, China \\ 157724554@qq.com
}

Keywords: Database principles; Course design; Blended learning mode; Flipped classroom

\begin{abstract}
This paper analyzes the problems existing in the current teaching of the course design of database principle, and then the blended learning theory were analyzed. Finally, many methods of hybrid learning theory, such as network teaching system, flipped classroom, MOOC and so on, were applied to the teaching process of the course design of database principles, and the teaching effect was analyzed. The teaching practice of three years shows that the blended learning model is beneficial to the teaching of database course design.
\end{abstract}

\section{Introduction}

To cultivate and improve the students' ability of comprehensive application of theoretical knowledge and practical ability is the guiding ideology of the construction of the applied university, and it is an important index for the implementation of teaching and the evaluation of teaching effect. Database curriculum design is a compulsory course for computer science majors, which is a practical course of database principle and application course. Practice teaching is to deepen students' understanding of database theory, method and technology content, let the students through participation in the whole process of database design and implementation, the application of reinforcement learning and fun, practical skills to design a database application system, so as to achieve the preliminary ability to develop small information system, complete the upgrade mission accomplishment. How to give full play to the role of the database curriculum design and achieve the desired teaching effect, is the goal of teaching reform. There are many disadvantages and problems in the teaching mode of the traditional, lack of cultivating students' innovation ability and the power of active learning, and blended learning emphasizes students' autonomous learning and individualized learning [1], can give full play to the main role of the students and innovative potential, so we will open up the teaching mode of the gradual introduction of database curriculum design. After careful preparation of open teaching and the implementation of teaching in the past 4 years, we found that the blended learning is a good reform direction of the database curriculum design.[2]

The problems existing in the course teaching of Database Course Design were analyzed in this paper, many methods of hybrid learning theory, such as network teaching system, flipped classroom, MOOC and so on, were applied to the teaching process of the course design of database principles, and the teaching effect was analyzed. The teaching practice in recent years shows that the blended learning model is beneficial to the teaching of database course design.

\section{The Problems Existing in the Teaching of Database Course Design}

Database curriculum design is generally 2 weeks (32 hours) of the concentration of practical courses in the database principle and application of the end of the semester after the end of the course. The curriculum design of the traditional teaching focus on a fixed computer room, by the teacher give 3 5 subjects, then the students selected and completed the design and development. At the end of the course, the students hand in the report and the teacher checks. After years of teaching practice, we found that the implementation of this program can complete the basic goal of teaching 
to a certain extent, but for the cultivation of innovative and applied talents are lack of motivation, gradually exposed many problems.[3] Specific reasons are as follows:

Database system is widely used in the real world, there are many excellent cases. The traditional curriculum design topics are limited to 3 5 fixed topics, such as library management system and student management system. The teacher usually describes the function of the system to the students, the students design and develop according to the function description in the process of system function, the system requirement analysis and function design are finished. However, this is a very important stage in the design of a real system, the students in the passive environment to complete the curriculum design, resulting in the enthusiasm of students is not high, the lack of innovative power; [4,5]

In the traditional teaching, the teacher pays attention to the student's design to complete the function of the system, but does not carry on the effective appraisal to the design quality and carries on the monitoring to the complete process. This will lead to some students in the same time in the design process to consider more thoughtful, ignoring the perfect system front, resulting in unsatisfactory results;

The function of the topic is given by the teacher, the basic function of the system is generally, but there are few requirements for system optimization, such as concurrency problems, security control, fault tolerance, mass data storage, etc.. As a result, many students only design and develop functional descriptions, but do not know in practical applications. The stability and optimization of system performance is sometimes more important than the system function itself. The result is that many students feel that the completion of a software system is not very complex, but in the employment and future work but the lack of a real system analysis and design capabilities. In teaching, teachers should guide students to realize the importance of system optimization and teach students how to optimize the database.[6,7]

\section{Methods \& Materials}

At present, the mixed learning is mainly based on the information technology, which is in line with the current trend of the development of the times and the main trend of social development. This paper mainly uses the following methods:

Network Teaching System

Network teaching system is a comprehensive teaching service support system. Based on network media and information technology, teachers can achieve the teaching, coaching, communication and students self-study, homework, testing and quality evaluation and other services, at the same time, it can provide real-time tutoring service for the students. [8]

Flipped Class Model

Flipped classroom is generally referred to as "reverse classroom teaching mode"". In traditional teaching, teachers are the master of learning process. The teacher is responsible for the classroom instruction, the arrangement homework, the usual and the final examination, the revision work and the examination paper and so on, the student coordinates the teacher to carry on the teaching activity. In the teaching process, it is difficult for the teachers to be individualized and diversified teaching. In the flipped classroom, the students become the master of teaching, teachers help students to complete the task of teaching. Students first preview the contents of the class before class, in class for their own difficult problems in the preview, there are key questions, to solve their own problems in a timely manner, to obtain more targeted knowledge. [9,10] Under the class for not understand the problem, do some homework, master more accurate knowledge. Therefore, in the flipped classroom, the classroom has become a "lovely" space for students to explore the exchange, teachers become students to solve the problem of an auxiliary role. Here, students use the Internet to use quality educational resources, not just rely on the teacher to teach knowledge. The role of teachers in teaching has changed, he is mainly to understand and solve the problems of students, to guide students to learn the right direction, the management of learning process, the organization of cooperative learning. Flip the classroom to make full use of rich information resources, so that 
students gradually become the protagonist of learning. Therefore, to improve the evaluation mechanism, promote the balanced development of education, while promoting the flip classroom more popular. [11,12]

\section{Result \& Analysis}

The open teaching of curriculum design has been carried out for 3 semesters, and the subjects are grade 2011, grade 2012 and grade 2013. From the perspective of the implementation process and effect, the open teaching of curriculum design is different from the traditional curriculum design.

Firstly, due to the opening of the time and place, students can combine the examination and answer time mechanism, more flexible arrangements for their own Time.

Secondly, the opening of the curriculum design content, stimulate the students' learning interest and enthusiasm. The topic of the student's thinking is broad, the topic and design of the system to take into account the actual application and demand, making the curriculum design is no longer the same works.

Thirdly, investigation of the object of teaching results show that the open teaching mode with more than $85 \%$ students, this teaching mode can not only play the students' learning autonomy, but also reflects the students' trust and tolerance, greatly improve the students' learning enthusiasm; about $20 \%$ of the students said in the curriculum design, will continue to improve themselves the work; there are about $10 \%$ of the students used to complete the established topic, to realize the task through their own research, selection, design and the difficulty, teachers should strengthen the encouragement and guidance on the part of students.

\section{Summary}

As a closely integrated curriculum, the curriculum design of the database needs to reflect the actual application needs, and train students to analyze, design and implement the system to solve the practical application ability. The mixed teaching of curriculum design can maximize the use of existing resources, expand the space and time for students to learn and improve their enthusiasm and creativity. 3 years of teaching practice shows that the mixed design of database curriculum design is a useful teaching model.

\section{Acknowledgements}

This paper is a report of the research project of teaching reform in the Information Engineering Institute of Yulin University.

\section{References}

[1] Y.P.Zhong, Y.J.Guo, X.Y.Luo. Application of Problem-Based Learning mode in nursing practice student teaching. 2015 7th International Conference on Information Technology in Medicine and Education (ITME). 2015

[2] T.Wiktorski, T.Hacker, R.A.Hansen, G.Rodgers. Experience with Problem-Based Learning in a hybrid classroom. 2015 IEEE 7th International Conference on Cloud Computing Technology and Science. 2015

[3] Y.P.Huang. Exploration on the construction of digital signal processing high-quality curriculum. Education and Vocation. 2014

[4] Li ke-dong, Zhao Jian-hua. General Theory and Application Model of Blended Learning. E-education Research. 2004 
[5] Z.J.Li. The Research on Course Reform of "Modern Education Technology". China Educational Technology. 2009

[6] Liu Cheng-kun. Study of Self-learning Activity Methods of Students Based on Internet Environment. Teaching and Management. 2007

[7] Armando Fox. From MOOCs to SPOCs, J. Communications of the ACM. 2013 (12)

[8] Ma Dan. MOOC students "high dropout rate". The Xinmin Evening News. 2013

[9] Jeremy Strayer. How learning in an inverted classroom influences cooperation, innovation and task orientation, J. Learning Environments Research. 2012 (2)

[10] W.H. Liu. Thinking and Practice on the Construction of Signals and Systems Course in Technology Applied University, A. Proceedings of 2016 International Conference on Physics and Physics Education (ICPHY2016) [C]. 2016

[11]G. Chinnery: "Going to the MALL: Mobile Assisted Language Learning", J. Language Learning \& Technology .Vol10, No. 1, P. 9-16.

[12]Lu C, Chang M, Kinshuk, et al: Usability of Context-Aware Mobile Educational Game, J. Knowledge Management and E-Learning. Vol.22 (2011) No.3, p.448-477. 